\title{
Integrating Social Scientific Perspectives on the Quantified Employee Self
}

\author{
Thomas Calvard \\ Business School, University of Edinburgh, Edinburgh EH8 9JS, UK; thomas.calvard@ed.ac.uk
}

Received: 7 August 2019; Accepted: 11 September 2019; Published: 15 September 2019

\begin{abstract}
A key technological trend in big data science is that of the quantified self, whereby individuals can self-track their health and well-being using various sources of information. The aim of this article was to integrate multidimensional views on the positive and negative implications of the quantified self for employees and workplaces. Relevant human and social scientific literature on the quantified (employee) self and self-tracking were drawn upon and organized into three main influential perspectives. Specifically, the article identified (1) psychological perspectives on quantified attitudes and behaviors, (2) sociological perspectives on sociomaterial user construction, and (3) critical theoretical perspectives on digital power and control. This article suggests that the three perspectives are complementary and can be usefully integrated into an embodied sensemaking perspective. Embodied sensemaking views the employee as a self-conscious user of big data seeking to make sense of their embeddedness in wider digital and organizational environments. This article concludes with implications for protecting employee agency in tension with employers' big data strategies for governing and managing the performance of quantified digital employee selves.
\end{abstract}

Keywords: quantified self; well-being; employees; self-tracking; big data; sensemaking

\section{Introduction}

The term 'quantified self' is generally attributed to two editors of Wired magazine, Gary Wolf and Kevin Kelly, in 2007, coined to describe the use of new devices and technologies to obtain automatically collected data about personal activities and everyday experiences, turning them into numbers (Lee 2013). The personal and social appeal of data-enabled self-insight, experimentation and management makes the quantified self a key technological trend in big data science, with implications for healthcare, well-being and workplace power relationships (Moore and Robinson 2016).

Where human and social scientific literature on the quantified self is still emerging and scattered, the aim of this article was to offer some necessary theory-building and integration on quantified (employee) selves, and their positive and negative implications for employment relationships and work. For instance, defining the quantified self involves connections with self-improvement, wearable technologies, daily activities related to well-being (e.g., working, eating, sleeping, exercising), personal information accessible from big data sources, and communities of users with shared interests in self-tracking and lifestyle changes (Kenton 2018).

The quantified self-concept and/or movement sits uneasily alongside critical concerns about big data activities carried out by powerful state and corporate interests-surveillance, monitoring, privacy invasion, control and commodification (Zuboff 2015). The debate is polarized, with these concerns co-existing alongside more positive narratives of empowerment and self-knowledge through greater access to and understanding of data about oneself (Sharon 2017). In terms of employee well-being and digitally transformed workplaces, the quantified (employee) self reproduces tensions around power, autonomy and control in the employment relationship (Fleming and Sturdy 2009). What is at stake for citizens and employees is a democratic right to participate in science, learning and experimentation 
that involves the self, where, in one sense at least, ' $n=1$ ' (Swan 2012a). The concerns and debates are not new, but they continue to evolve and shape new forms of work quality and stakeholder relationships. Indeed, the established literature on work and technology continues to emphasize forms of technological control in relation to worker algorithms, platforms and freelance work in the 'gig' economy (e.g., Wood et al. 2019). Similarly, literature on the evolving histories of science, technology and knowledge production continues to emphasize how 'big' its scope can be, while learning needs to be humble, participative and distributed in the face of uncertainty and the unknown (Galison and Hevly 1992; Jasanoff 2003).

The quantified self and big data give rise to three main tensions: transparency versus secrecy; self-expression versus conformity; and data-power imbalances between institutions versus individuals (Richards and King 2013). This article reviews and organizes multidimensional research on the quantified self as it relates to big data tensions and human attitudes and behaviors regarding technology, work and well-being. Doing so enables theory development on understanding the practices, values, and sensing/knowing capabilities needed to navigate the above tensions more successfully (Calvard 2016; Sharon 2017). Definitions of the quantified self imply quite a personal, intimate relationship between our self-concepts and the data we generate and capture; data that can then subsequently be appraised and made sense of, to further shape our sense of self in relation to others (Lambert 2016). This is complicated by the activities, processes and power relations that accompany the collection of the data and how it is used to serve particular ends around employment and well-being.

Encounters between the quantified self and the operations of big data often involve actors making 'subject access' requests for personal data from large organizations (Walby and Larsen 2012). The data proffered is then confronted by the actor in terms of the scope, quantity and quality of what it can tell them about their personal status and relationship to the world. For instance, researcher and author Carl Miller asked 80 companies for access to copies of all the data they held about him. Around 20 replied, providing personal data that ran to 7000 pages in length (Miller 2019). Similarly, Austrian law student and European privacy advocate Max Schrems secured 1200 pages and 57 categories of personal data about himself from Facebook (Solon 2012). Interestingly, the reactions to confronting a reconstruction of one's digital self tend to be mixed-skeptical, indignant, amused, alarmed-and often, the actor does not recognize a coherent or consistent picture of their 'real' self in the data produced (Miller 2019).

Regardless of how the self is quantified, it represents personal attempts to make sense of ourselves in our daily work and lives from within a complex world of 'datafication', where large amounts of data are being generated and processed around us (Lycett 2013). However, the activity of 'self-tracking' more broadly has a socio-technical history of at least 100 years, from the weighing scale to the wearable devices of the twenty-first century, with problematic claims that it will lead to self-knowledge and self-care (Crawford et al. 2015). Problematic because they enable big data-driven interests such as employers and organizations to encroach on and penetrate into work, consumption and leisure. However, the relationship between data and self-care is complicated because the technology outsources tasks of lifestyle management to an extent that may be welcomed and deemed beneficial to many users, sharing in and assisting in taking responsibility for self-regulation of well-being (Schüll 2016).

The effects of self-quantification depend on 'who' is quantifying, but also 'how' quantifying is done, and whether it has to involve only numbers or not. Synonyms and related terms, such as self-tracking, life-hacking, life-logging suggest reflection and interpretation of data that goes beyond quantification to include media and storytelling, or a 'qualified self' (Humphreys 2018; Lupton 2016a). In many ways, diaries, calendars, charts and autobiographical writings reflect states and processes that accompany the production and consumption of data relating to a personal sense of self.

Self-tracking as an idea has a long history, but it continues to evolve through big data technologies, making types and quantities of data accessible as evidence for organizing daily work and life (Neff and Nafus 2016). In employment, these activities filter into the workplace culture-its competitiveness, playfulness, politics, creativity, health, learning and decision-making (McAfee and Brynjolfsson 2012). In a workplace of quantified employee selves, meaning has to be 
created through a properly cultivated and holistic sense of normativity, improvement, relationships and inclusion/exclusion (Bietz et al. 2016).

The problem of interpretation is that personal data "often reveals more than its designers intended, yet less than is required to be useful" (Neff and Nafus 2016, p. 69). In other words, the presentation of a source of data alone can only tell you so much. Bietz et al. (2016) expanded this point further, urging big data stakeholders to come together and consider what data means to diverse parties. Big data is personal, political and relational, and needs to be treated in a correspondingly multidimensional fashion. The data has top-down and bottom-up elements that unfold through practices and activities, changing how employers and co-workers monitor and coordinate, as both objects and subjects of data quantification (Levy 2013).

Keeping track of trackers and tracking poses organizational and individual challenges. Employees place great emphasis on performance and achievement data and how it shapes their identities and well-being (Walker and Caprar 2019). Human resource (HR) functions may lack the various capabilities needed to manage all data analytic interactions and interests between employers and employees (Angrave et al. 2016). Both readiness and resistance to change may be present in organizations when it comes to embedding cultures of wearable devices and big data (Shah et al. 2017). Conceptually and practically, a multidimensional approach is required. This applies not just to data and performance, but also employee well-being-with complex personalized trade-offs existing between psychological, social, physical and financial domains of health (Grant et al. 2007).

Therefore, this article proceeds by reviewing the quantified self in conjunction with these multidimensional issues of data, well-being, employment and sensemaking. The human and social sciences offer different ways of theorizing their inter-relations that can be viewed as complementary.

\section{Big Data, Well-Being and the Quantified Employee Self}

Big data tends to be defined in terms of its bigness (volume, velocity and variety etc.), and being too big for human analysts and conventional computing power to analyze (Calvard 2016; McAfee and Brynjolfsson 2012). However, in reality, it blurs with many diverse uses, technologies and trends (Angrave et al. 2016).

The quantified self is difficult to precisely specify and review because it often refers to the general trends for data to be accessed by populations of consumers, rather than employees or other groups per se. Organizations now face a general blurring of a portfolio of relationships beyond just customers-employees, families, communities, teams and other partners are all likely to orbit data flows and transactions (Plouffe et al. 2016).

In general, employers are urged to think about data analytics as a way of competitively and distinctively understanding their workforces (Davenport et al. 2010). Technology has important connections with employee well-being, acting as both a demand and a resource around issues of accessibility, control, monitoring, and feedback (Day et al. 2010). Recent surveys of employees' perceptions of a future workplace dominated by smart technologies show uncertainty about jobs or skills, negative emotional reactions and a lack of attachment to a single organization (Brougham and Haar 2018).

Quantified selves exist in diverse domains and modes, with self-tracking data and digital surveillance of individuals ('dataveillance') being used by a range of diverse actors in diverse contexts (Lupton 2016b, 2016c). Lupton (2016b), an influential scholar of the quantified self, theorized its 'function creep' into five modes of self-tracking-private, communal, pushed, imposed and exploited. Therefore, workplace leaders need to be mindful of how these different modes affect employees' well-being and workplace cultures. Employees may feel empowered and cohesive, or coerced and invaded.

Employees are actively engaged with data in ways that go beyond a mere 'data fetishism' emphasizing objectivity and truth; they also quantify themselves as a form of mindfulness, resistance 
against norms and in narrative communication with others (Sharon and Zandbergen 2017). In short, employees are 'quantifiers' and 'quantifying', not just 'quantified' (Sharon and Zandbergen 2017).

The technologies underpinning self-quantification include smartphone apps, wearable devices and biometric sensors (Swan 2013). These technological developments dovetail with an interest in analyzing and improving performance measurement in factories, offices and other workplace settings (Wilson 2013). Wilson (2013) traces wearable devices, feedback and performance to at least 1965 and the remote monitoring of NASA astronauts through to present day possibilities of measuring EEG brain waves and micro movements. Currently, it remains unclear whether wearable workplace devices will become widespread beyond the physical activity of checking a smartphone. Successful cases of workplace implementation tend to ensure individual privacy, team and managerial access to aggregated data only, straightforward opt-out provisions and a collaborative emphasis on both individual and organizational benefits (Wilson 2013).

A survey of American Occupational Health and Safety Professionals revealed a small majority in favor of using wearable sensors to track employee well-being, but also concerns and barriers to adoption regarding privacy, compliance, material quality/costs, and distraction (Schall et al. 2018). Perhaps the strongest positive argument in favor of wearable employee sensors is that HR functions, teams and managers can more effectively manage employee health and safety risks, such as fatigue, posture, strain and other exertions (Becker and Smidt 2016; Schall et al. 2018). This is bolstered by the prospect of better supporting an ageing workforce, where even small data-driven adjustments to workspaces, schedules and equipment can have positive effects in maintaining teams' productivity and well-being (Loch et al. 2010).

At the same time, however, the tension with privacy around the tracking of very personal, intimate employee activity remains an ever-present issue. Often, the topic is approached in terms of personalized medicine and fitness benefits for millions of users of popular apps and devices. However, a lot of support is generally needed to help users understand devices and what standards of data quality are (or are not) being adhered to by big-name brand devices, such as FitBit, Jawbone and Nike Fuelband (Hoy 2016).

Many wearables represent 'everywear', tethered to the routines of the body and not taken off if they are to be used to support 'ubiquitous healthcare' (Gilmore 2016). Self-quantification thus complicates our relationship to the everyday activities of our bodies and socializes us into new power and technological relations of what we know and experience of ourselves. Employees may report ambivalence amid concerns of 'becoming their devices' - part of a process of questioning moral aspects of workplace wellness imperatives and playing around with how to fuse ideas of work, pleasure, leisure and health (Richardson and Mackinnon 2018).

There is a danger that the quantified self becomes all the users' or employees' responsibility, with regulations and legal protections being scaled back in line with a neoliberal political economic agenda of individualism and self-sufficiency (Calvard and Sang 2017). In the cases of nurses and midwives for example, their continuous professional development (CPD) constitutes a set of self-tracking and monitoring responsibilities but is not always adequately supported by employers and professional associations (Lanlehin 2018). This again blurs boundaries around work demands and divisions of labor, and who is responsible for handling information, along with using it to make decisions. It raises questions about the purposes of employer and employee (self-) surveillance in evolving forms of work, such as the 'gig' economy (Wood et al. 2019).

Healthcare contexts are often instructive for workplace settings more generally. Here, the notion of a 'quantified patient' means that patients can be supported to log and feed their own personal information into clinical workflows and decision-making frameworks that meet stakeholder needs and interests (West et al. 2016). The ' $4 \mathrm{P}^{\prime}$ ' project of data-driven medicine-predictive, personalized, preventive, and participatory-could be read across as an HR or employment strategy for other workplaces more widely too (Swan 2013). These data-driven frameworks flow in part from so-called 
'mode 2' knowledge production tendencies that reimagine science, curiosity, and innovation as things all employees and citizens might be more democratically involved in (Gibbons et al. 1994; Nowotny 2010).

Overall, the quantified self seems to be a very double-edged site where big data trends reflect the coming together of institutional and individual complexity. On the one hand, problems of workplace surveillance and control remain considerable in terms of asymmetrical power relations in accessing and analyzing data (Rosenblat et al. 2014). On the other hand, the quantified self involves collaborative opportunities for personal and reflective learning-with much depending on democratic workplace designs and applications (Rivera Pelayo 2015). One 24-week experiment with an extensive 'Quantified Workplace System' in two European offices notes many mutually beneficial applications of the technology, but co-existing with the need to carefully ensure privacy, trust and device compatibilities (Mathur et al. 2015a). It is hard to talk about the self being quantified without acknowledging how the workplace as a whole is also quantified.

The quantified self reflects one lower level of (big) data intimacy, nested within higher levels and structures making up an ecosystem. More critically, this is shaped by a struggle over what the data means. The minds and bodies of employees are vulnerable to control by those with authority to define words like 'truth', 'self', and 'wellness' as measured by data (Moore 2017). This is the quantified self at its most ideological, where employees may be trying to figure out what their data means at a personal level and what it is for. Language evolution also reflects these struggles; not just 'quantifying', but 'logging' and 'hacking' the details of one's life by apprehending data about them that we might not otherwise have been aware of-our habits, environments, and interactions. Often, these ideas are related to self-improvement but can produce a sense of the useless and harmful where data is used to compulsively chase efficiency and order in a way that is self-defeating for other qualities of a full and meaningful life (Cederstrom and Spicer 2017).

What is clear is that the quantified self is a disruptive change that invites more engagement with more data about the self. This data is relatively continuous, intimate, and suggestive of feedback about how to optimize our lives (Swan 2013). There are many potential issues and questions facing different employment contexts, such as user design and inclusion. The next three sections of this article represent three overlapping and complementary ways of organizing and integrating literature on the quantified employee self-psychological, sociological and critical theoretical. Concrete examples and case studies are given where possible (e.g., from healthcare, sports), but workplace and employee examples are still emerging and can be difficult to locate and meaningfully isolate from surrounding trends. The quantified self is embedded in the quantified workplace and wearable consumer trends, but it can quickly expand beyond an individual project.

Notable workplace examples might include cases such as the armbands and wristbands of warehouse workers gathering and distributing goods for Tesco/Amazon, or the software company Kronos offering heart rate sensors for nurses to manage fatigue on long shifts. In addition, companies like CultureAmp are providing tracking tools adopted by many companies to monitor real-time employee engagement emotions and allow employee voice (e.g., see Bersin 2014). However, public trust, employee adoption, and the purposes self-tracking analytics are put to remain mixed and variable-making a multidimensional understanding of the move from 'quantified self to quantified employee' even more important.

It is likewise important to note that the three demarcated approaches below do not reflect hard and fast distinctions and may involve blurred disciplinary boundaries and internal divisions/stances. Questions of how to integrate them are addressed later, and a fourth perspective is put forward as a pragmatic compromise position linking the psychological, the social and the societal-that of the quantified self as an ongoing process of embodied sensemaking activity.

\section{Psychological Perspectives on Quantified Attitudes and Behaviors}

Psychological perspectives on the quantified self, as characterized here, focus on the attitudes and behaviors of the individual employee or user as they engage with data about themselves. 
Psychological reactions in the workplace are often summarized as an $\mathrm{ABC}$ acronym-affect, behavior and cognition-or 'hearts', 'deeds' and 'minds' (Kark Smollan 2006).

A psychological perspective on the quantified employee self is quite limited to the experience of the individual, but also in-depth in its appreciation of how emotions, thoughts/beliefs and actions inter-relate around personalized data engagement. Mathur and colleagues (Mathur et al. 2015b) titled one of their workplace field studies 'tiny habits in the giant enterprise', emphasizing how an initial psychological need to belong to a self-quantification initiative gradually translates into forms of participation and habitual routines.

Psychologically then, the prospect of a quantified employee self involves certain attitudes and behaviors with regards to approaching devices and data. Needs, motivations and values affect usage and engagement- to feel included, to participate, reflect, observe, act, and learn. The digital workplace also reciprocally affects the psychological experience of the quantified employee self. Belk (2016) argues that digital trends like the quantified self psychologically 'expand' and 'extend' self-expression and identity. Three key concepts are dematerialization (attachments to digital/virtual objects), re-embodiment (self-representation beyond our physical bodies), and co-construction (data from others shaping how we see ourselves and are seen). Here, a psychological challenge is employees' self-management of this 'extended self'. Some data may be knowingly engaged with, other data unknowingly extracted/modified, and other psychological experiences-such as social or emotional activities—not easily quantified (Belk 2016).

The quantified self reproduces measurement tensions in social psychology about what exactly is being measured. Typically, psychological data come from self-report survey questions and small movements or expressions of body language (Baumeister et al. 2007). More complex behaviors are often deemed more desirable and insightful, but psychologists also need to seek unobservable processes that are driving them (Jetten and Haslam 2018). In the workplace, this means that the psychological tension is between data driving behavioral change versus understanding the nature of the behavioral change and how it is produced.

Understanding employees' quantified selves psychologically depends on how behavioral change is framed and understood. Ploderer and colleagues (Ploderer et al. 2014) argued that five approaches can help move the psychology of personal consumption of big data beyond crude prescriptions to engage/avoid courses of action. These are social traces (motivating pieces of data from other users), social support (forms of mediated exchange and aid), designing for collective use (scaling up or involving particular groups), reflection-in-action (real-time feedback during activity), and reflection-on-action (feedback and data representation after activity). Kersten-van Dijk and colleagues (Kersten-van Dijk et al. 2017) reviewed theories and studies on 'personal informatics' (another term for the quantified self), self-insights and behavior change and found some limited support for a self-improvement hypothesis. They concluded that further research is needed to better model how system design features relate to (de)motivational states and whether beneficial user outcomes are lasting or not. These involve testing simple components, representative samples and process/outcome evaluation. For users limited in prior experiences, systems need to be highly tailored, motivating and empowering-which requires a balance of autonomy and engaging technological features (Rapp and Cena 2016).

For employees to achieve lasting data-driven psychological change, consideration should also be given to habit formation. Effective habit-building can take several months, benefiting most from self-tracking technology that provides sophisticated and interactive 'reminders' (Stawarz et al. 2015). This, in turn, leads to data and technology that support specific activity recognition, such as eye tracking for learning and development purposes (Kunze et al. 2013).

The psychological sophistication of the technology and the employee as user can both vary dramatically. Here, the term 'quantified self' obscures the distinction between more mundane (but prevalent) self-tracking of daily activities and more sophisticated (but infrequent) 'biohacking' by highly committed users (Didžiokaite et al. 2018). Indeed, many employees may confine their use 
and reject certain activities altogether. It seems worthwhile for workplaces to keep returning to the psychological issue of how intimately employees are really able to fulfil the 'know thyself' maxim. Quantifying technology may be effective for some limited aspects of behavior, but struggle to faithfully and lastingly reflect deeper psychological states and dynamics (Rapp and Tirassa 2017). There is a need to learn more from rich accounts of self-experimentation (Roberts 2012) and temporal accumulations of personal data that involve people tracking their long-term memories and histories (Elsden et al. 2016).

A fuller review of other psychological and technological streams of research is beyond the scope of the current paper-attention to internal divisions within psychology and overlaps across other disciplinary domains is advised. For instance, the idea from behavioral economics that behavior can be 'nudged' by the presentation of data in different decision formats has distinct psychological implications for the quantified self (e.g., Schüll 2016). The playful motivating principles of 'gamification' in making data-driven self-management more like a (video) game is another relevant psychological framing (e.g., Hassan et al. 2019).

Workplace psychology has both positive and negative extremes to be aware of when assessing employee experiences (Fineman 2006). The quantified self is likely to have positive and negative psychological nuances across technologies, employees and experiences. Employee behaviors that affect and reflect well-being are at the sharp end of these psychological processes. On the more positive side, we might expect well-designed and user-friendly wearables and devices to continue to support lasting and healthy attitudinal and behavioral changes, according to careful interventions and evaluations. Behavior change will continue to evolve as our reflexive relationships with our own brains and bodies deepen and are enriched through data (Rowson 2011). On the more negative side, we should remain concerned about evidence for pathologies exacerbated by or related to employees' quantifying activities. These include forms of Internet and smartphone addiction (e.g., Griffiths 2010), as well as the 'sensor mania' as humans adapt to a greater density of sensors and flows of information (Swan 2012b).

\section{Sociological Perspectives on Sociomaterial User Construction}

In this section, sociological perspectives were distinguished by 'zooming out', to an extent, from the individual intimacy of psychological perspectives on employee quantified selves to emphasize more the user's social background and context of use (Ayobi et al. 2016). This heightened commitment to the social context of technological effects is reflected in terms like 'sociomaterial' and 'sociotechnical' —where technology cannot be meaningfully separated from the roles, groups, spaces and practices affecting and affected by its use (Davis et al. 2014; Orlikowski and Scott 2008).

While it is challenging and not necessarily desirable to unify this perspective-the work of the sociologist Deborah Lupton is certainly a well-established and key exemplar, with a 2016 book on the Quantified Self that gives a thorough overview of self-tracking practices, hybrid configurations of humans and technologies, and various cultural and political organizations, stakeholders and domains of application (Lupton 2016c). This sociology of personal informatics acknowledges the quantified self as involving profoundly social practices and cultural meanings, the technology being deeply linked to the pleasures, inequalities, and diversity of modern life (Lupton 2014). Under a sociological approach, users have some social agency to come together and reflect on their quantified selves and self-tracking activities. Lupton (2017) discussed 'sociotechnical imaginaries' where people imagine future ideals, and 'lively' interactions between users and wearable devices. At the same time, there are many critical accounts of market failure and many devices and apps failing to achieve any positive, lasting use (Lupton 2017).

Evidence directly relating to workplaces and employees is still fairly limited, but there is sociological research on specific practices that offers insights into self-tracking employees and employment cultures. Not all are unequivocally positive. Whitson (2013), for instance, expressed concern about the tensions between playful gamification and more serious surveillance, and the social effects of making "weight loss, workplace productivity, educational advancement, [and] consumer loyalty" (p. 163) seem like a game. She discussed the workplace examples of call center and hi-tech work redesign, with the crucial 
concern that the work-play contradiction "kills the motivation to play and instead motivates workers to thwart and resist the systems that have attempted to mislead them and take advantage of their playful tendencies" (Whitson 2013, p. 174).

The hierarchies, monitoring and power relations making up the social context of workplaces make engaging and autonomous self-tracking a very contestable prospect for improving employee well-being. However, surveillance (and playing games) is not the only social practices in play for employee quantified selves. To the extent that employees are participating selectively and voluntarily, some may be diligently collecting and exploring personal data and discussing it to identify 'workarounds' and improvements to their lives. Choe and colleagues (Choe et al. 2014) found this to be the case for 52 enthusiastic international users who reported health, work performance, mindfulness, and learning benefits, while challenges were also reported in terms of ensuring sustained, rigorous experimentation and analysis.

Importantly, the tracking is inherently social and associated with social practices, entangled with but also distinct from the technology itself (e.g., spreadsheets, devices, apps). Measurement and communication are two major social practice areas. On communication, Lomborg and Frandsen (2016) identified three forms in self-tracking-with the system, with oneself, and with social networks of peers. These supported needs for identity, competence and agency in a gender-balanced sample of Danish fitness trackers (Lomborg and Frandsen 2016). In a similar study of 11 Australian digital self-trackers (e.g., Fitbit, Apple Watch devices), Lyall and Robards (2018, p. 113) identified three simultaneous "roles of self-tracking: 'tool', 'toy' and 'tutor'". In other words, self-tracking is as a tool that is useful, a toy that is fun/engaging, and a tutor advising flexible routines. Reciprocal interactions unfold "between devices, data and users" (Lyall and Robards 2018, p. 114). Focused on the workplace, Stein and colleagues (Stein et al. 2019) studied digital tracking ('datafication work'), accountability and meaningfulness in a sample of U.S. professional academics using a performance management system. They found that meaningful work with data depended on a supportive institutional context, a well-designed system open to feedback and customization, and recognition of users struggling with how the technology was implemented locally (Stein et al. 2019).

Sociological perspectives on quantified selves are also useful for placing more emphasis on socio-demographic categories and domains of users. As noted above, healthcare is particularly salient, with the notion of a 'quantified' patient. Despite the slow adoption of new technologies and regulatory protections, the quantified patient offers opportunities for patients, researchers and providers to better monitor and diagnose the quality of health outside of costly, inefficient hospital visits (Majmudar et al. 2015). Chronic conditions such as heart failure are managed through many combined human and technological components-health care teams, domestic households, equipment and protocols (McDougall et al. 2018). Beyond patients, consumers using popular devices like Fitbit to track fitness activities experience 'biopedagogy' as they learn and train their bodies in healthy living. Everyday practices include productivity boosts, social networking, coaching, and 'biological citizenship', where well-being expertise and responsibility can develop (Fotopoulou and O'Riordan 2017). There are many analogous implications here for the social practices and contexts of managing employee well-being and performance at work.

Substantive socio-demographic analyses of quantified selves are relatively rare but reflect important sociological considerations. Devices like Fitbit are branded in gendered ways toward young women (Fotopoulou and O'Riordan 2017). Wearable technology also draws renewed attention to women's bodies, health, fashions and sexualities (Wissinger 2017). The prospect of ageing populations and safe, healthy and sustainable workplaces highlights the potential for closer tracking and management of age and well-being risk factors, job requirements, ergonomic supports, and transitions in/out of work (Lavallière et al. 2016).

Internally, sociology may involve many differing schools and influences, some linking it externally more closely to psychology and critical theory than others. Overall, sociological perspectives on quantified selves and well-being as classified here emphasize the 'co-evolving' nature of social life 
alongside technological developments. Markets and metrics invite us to set up a 'laboratory of the self' for our lives in relation to larger social structures like communities and organizations (Kristensen and Ruckenstein 2018). It is a voyage of participation, discovery, and at times, resistance. Digital tracking involves navigating trade-offs in social contexts and in practices-different wearable devices, levels of data literacy and concessions for giving up data (Iliadis and Pedersen 2018). Eventually, this line of thinking broadens and deepens into the more critical view of social systems presented in the next section below. Here, organizational power relations and control involve forces applying data quantification 'from above' that are resisted 'from below' by data-generating employees as they question means, ends and who benefits most from data quantification (Woodcock and Johnson 2018).

\section{Critical Theoretical Perspectives on Digital Power and Control}

Critical management studies (CMS) continues to evolve alternative approaches to understanding organizations and employees, based on Marxist, feminist, postmodernist, poststructuralist, psychoanalytic and environmentalist schools of critical theory (Adler et al. 2007). The variety of critical theoretical perspectives on offer for understanding societal power and control in relation to technology, work and organization is vast, with many internal divisions and bodies of work beyond the scope of this article. However, some brief connections with the quantified employee self can be sketched in review to illustrate their distinctive value. All are concerned with challenging dominance and instrumentality and engaging in critical questioning and social justice issues through education, intervention and activism. They have only been partially applied to specific technological trends like the quantified self, but extant research has shown their potential and complementary value in conjunction with the more psychological and sociological research reviewed above.

This perspective is further 'zoomed out' in the sense of critically reflecting on what it means for most or all employee selves to be quantified, even those not directly engaged still being monitored and accounted for, and perhaps excluded or disempowered. An example of an established figure here is Phoebe Moore, with a suite of co-authored articles on the political economic effects of quantification as a management technique. For instance, Moore and Robinson (2016) developed a 'new materialist' perspective on the neoliberal workplace, highlighting the anxieties and risks associated with employees' having to constantly measure and account for productivity and well-being. Quantified employee selves become intensely competitive, precarious, and objectified and divorced from the challenging realities of laboring bodies. Where work is dirty or dangerous, quantifying activities may intensify these issues through performance management and efficiency demands, rendering work disposable or amenable to replacement by others/machines. Moore and Robinson (2016) drew on concrete examples of modern Amazon and Tesco warehouses, with similarities to older Ford factory production lines based on Taylorist 'time and motion' measurement of workers. The quantified self becomes something alienated and disciplined in the labor process, carried over and intensified through precarious forms of modern contracted office work and freelance, zero-hours work in a 'gig' economy (Moore 2017; Wood et al. 2019).

The ethical question emerges of how to regulate employee well-being (Moore and Piwek 2017). Consumer benefits exist in tension with how workplaces co-opt them as part of a wider 'value chain' or 'business solution'. The most negative scenario can be painted if we consider a 'new normal' context where legal responses are slow, productivity is hard to measure digitally (e.g., knowledge work), and pressures to adopt technologies are high, along with stigma for opting out (Moore and Piwek 2017). Newer forms of work design and management practices like 'agility' draw on tracking technologies to create new employee experiences, but ones invaded and colonized by additional 'affective labor', such as showing resilient emotional responses to challenging working conditions (Moore 2018). Ultimately, workers become more aware of their bodies and emotions and what cannot easily be measured as affecting their performance, raising the question of how they might organize to resist 'what cannot be measured' (Moore and Robinson 2016). 
Concerning power, knowledge and the quantified self in various populations, organizations and institutions is the work of 20th century philosopher and critic Michel Foucault. His concepts predate digital technologies but remain relevant and historically powerful. Ajana (2017) applies Foucault's concepts of 'biopolitics' (social and political power over human life) and 'biopower' (subjugation and control of bodies and populations) to explore ethical and political issues concerning the quantified self and digital health. In health terms, the quantified self is an ecosystem with incentives for workplaces, insurers and healthcare organizations to keep health costs down and prescribe individual self-control. There are also possibilities for sharing data and communal solidarity, although individual and communal privacy and responsibility require additional supports (Ajana 2017).

Foucault also wrote about 'technologies of the self' as ways in which individuals can operate on and transform states relevant to their well-being. Gabriels and Coeckelbergh (2019) argued that these are never morally neutral and always involve differentiation, examination and competition with others' tracking activities. Whitson (2014) discussed the prospect of 'Foucault's Fitbit' and again linked the quantified self with gamification, but where control is diffuse. People are 'governed', but also engage in 'care of the self'-self-direction and moral reflection with personal data. Essentially, Foucault's views as updated here point to a complex system of power relations in which "we undertake this quantification of the self under our own free will. We become self-regulating agents. Yet governing institutions are not wholly absent. They only appear to be" (Whitson 2014, p. 349). The outcomes here depend on critical engagement with power, politics and struggles for control.

Other critical research moved further downstream, contextualizing these broader critical theorizations. Catlaw and Sandberg (2018) found that tracking websites involved discussion of norms, practices and expertise for using data about the self, but increasingly defined what it might mean to be a 'good' or 'governable' data citizen in an 'info-liberal age' concerned with democratic big data management. In other words, our actions and conduct and possible selves are always broadly influenced by other people and agencies, infused with political ideas about big data and well-being. A critical question here concerns what kind of self or subjectivity is produced by the powers that be. Scholars like Till (2014) have argued that it is an entrepreneurial self, where activities like exercise are accompanied by forms of digital and immaterial 'labor'. A Marxist view highlights that users produce and consume data in cycles of reflection and action, while corporations commodify the activities, extracting value while offering no compensation for the data yielded. Whether or not this is deemed a societal problem depends on how one views the energy expended on data generation, and whether or not it results in greater public goods over time (Till 2014).

The quantification of beauty and psychological well-being is another issue. In the case of gendered and neoliberal cultures of digital self-monitoring, this is where critical theorists have started to combine Foucault with feminist perspectives. Beauty apps have changed the way users gaze on women's idealized beauty and appearance, amounting to surveillance in a problematic media culture that has women wrestling with supporting versus competing with one another (Elias and Gill 2018). This leaves gender, well-being, and self-tracking in workplaces at an important crossroads that holds for other diverse minorities. On the one hand, powerful patriarchal interests in health, beauty and fashion industries will impose ideals of femininity based on greater data gathering and surveillance to promote 'rigorous body projects' that seek to correct and project women's bodies (Sanders 2017). On the other hand, there is an important (cyber)feminist resistance inherent to the quantified self where supportive 'sisterhoods' of women connect through empowerment with mantras like 'our data, ourselves', with networks and movements to drive just and inclusive digital health outcomes (Levina 2012).

These political and cultural tensions unfolding in the digital/virtual arenas of the data economy seem likely to continue to affect employee experiences in workplace cultures too, if only because they affect what 'counts' and what is 'counted', online and off (Moore and Robinson 2016). 


\section{Big Data, the Quantified Self and Embodied Sensemaking}

Finally, a fourth social scientific approach to theorizing the quantified employee self is discussed, one based on an embodied sensemaking perspective, treating the employee as a self-conscious user of big data seeking to make sense of their embeddedness in wider digital and organizational environments. This approach is briefly outlined as a versatile and pragmatic way of integrating the three complementary forms of research reviewed above, focusing on ongoing cycles of data interpretation and revision. Specifically, a sensemaking perspective can be deployed to balance the psychological intimacy of personal data with the other social layers of experience and embeddedness in wider big data environments (Calvard 2016), while leaving some room for incorporating critical concerns and reflections as well (Allard-Poesi 2005).

A sensemaking perspective is often linked to Karl Weick's work in organizational behavior and can be applied to many social and cognitive phenomena, given its general concern with how actors interactively seek to interpret, imagine, and 'make sense of' their surroundings over time. In his seminal book, Weick (1995) grounds the overall perspective in seven general properties-identity, retrospection, enactment, the social, ongoing processes, cue extraction, and favoring plausibility over accuracy. Many of these principles can be applied to how users and organizations interpret, learn from, and make sense of 'big data' over time as it is generated in real-time (e.g., Calvard 2016). The idea of a body and self, situated in time and space, continuously trying to understand actions and representations (in data flows) constitutes a powerful resonance between sensemaking and the quantified employee self.

Sensemaking is not the only option for linking psychology, sociology and critical theory. However, it indicates what is important to any such integration effort-the pragmatism of linking wider structures of work and employment to the more personal activities of digital self-tracking. Self-tracking is recognized as ongoing and involving how we might want to become a changed person based on our transactions with others and reflections on our unfolding choices or courses of action (Elkjaer and Simpson 2011). Bakke and Bean (2013) have also proposed that sensemaking is well-placed to be elaborated to include material and embodied aspects. Interpretation is affected by physical objects and environments as well as the physical activities and movements of our bodies. This relates back to the wearable devices and physical activities associated with the quantified self. Personal data is not processed in an abstract, automated and disembodied way-it is repeatedly worked out in actions, reflections and experiences.

Furthermore, sensemaking can also be elaborated to allow for how interpretation takes place across humans and technology in complex systems where intelligence and comprehension are distributed (Klein et al. 2006). In the case of the quantified self, interpretations are continually being exchanged, shaped and updated between devices, sensors and users to craft positive and negative meanings. One implication of this for employees and quantified workspaces is the need for designs of devices and spaces that support meaningful interpretation and coordination of activities.

The body and social relationships with others can therefore be treated as one integrated sensemaking process which demands an equivalent 'anti-Cartesian' design process, going beyond the mind to incorporate sensing, acting, relating and (re)tracing (Van Dijk et al. 2014). Hummels and Dijk (2015) proposed that workplaces could be designed as embodied sensemaking studios, encouraging more physical, emotional and sensory stimulation. In an embodied sensemaking case study, Cunliffe and Coupland (2012) used videos of the 2001 British and Irish Rugby Tour of Australia to show how the athletes narrated and updated their experiences according to moments and experiences organized around more than just words, or more than just numbers/data. Accordingly, if the quantified self is to gain widespread workplace acceptance in relation to employee well-being, the senses and sensors need to be understood as they affect users' emotions and knowledge from moment to moment (Maslen 2017). Employees may ask sensemaking questions like 'what is this device telling me about myself that I don't already know?', 'what did I do differently that affected my data and feedback about myself this week?', or 'why am I feeling differently just now towards my data?' Studying Australian women's use of digital health technologies, Lupton and Maslen (2018) identified a human and technology 'sensorium', 
or environment where the strengths and limitations of devices were reflected on and discussed to access bodily insights and patterns.

Features of wearables devices and apps can therefore act as 'triggers' for employee sensemaking in how they use, critique and learn from technology (Griffith 1999). The reality of the technology and data is in the diverse reactions employees will have to it as they try to make sense of it. From the wider social sensemaking perspectives, user communities and platforms and even cities will also feed into these interpretive processes. Sharing platforms involve political discussions around community, commercial and hierarchical values affecting their sharing, tools and methods (Barta and Neff 2016).

In a discussion of implementing workplace well-being wearables, Mettler and Wulf (2019) identified both useful 'affordances' for safety awareness and more negative 'constraints' on freedom and privacy. Using a mapping methodology with experts and employees, they found evidence for five different 'mental models' or sensemaking orientations that employees might use to interpret using quantifying technologies. These were labelled: freedom-loving, individualistic, cynical, tech-independent, and balancer (Mettler and Wulf 2019). Framings reflect mixed feelings and concerns over organizational power and values. Another concrete work domain where quantified self-sensemaking is playing out is in sports, where athletes are deciding how to resist or embrace crossing a 'digital divide' involving sports organizations and the big data analytics that quantify their sporting performances (Baerg 2017).

Finally, while being connected to the body, sensemaking is also embedded in higher-level societal discussions about the self, which feed into interpretations involving power (Schildt et al. 2019). If the body is the 'who' of the quantified self, then societal discourse is the 'how' and the 'why'. As noted above, Foucault linked state and organizational power relations to subjectivity through terms like 'technology of the self' and 'care of the self'. Confronting large amounts of data about the self is in some ways unprecedented and risks saturating and overwhelming our sense of coherent identity (Gergen 1996). Since the idea of employees having a 'career', the idea of lifelong self-management has posed critical problems around how it acts as an individual burden of self-discipline in accounting for oneself (Grey 1994). What might it mean to have a 'quantified' or 'self-tracking' career, for instance?

Abstract constructions of 'wellness' and 'un-wellness' can mask inequalities behind employee data to suit powerful interests (Dale and Burrell 2014). The quantified self involves ethics when we consider what is (not) measured and valued in relation to an 'ideal worker' rendered by data-problematic when related to employees with disabilities and impairments, or dangerous/stressful performance conditions.

Thus, the quantified self poses new challenges and evolutions in discourses of both identity and its digital transformation (Nagy and Koles 2014), and the diversity and inclusion of minorities in data (Maragiannis and Ashford 2019). Perhaps the ultimate sensemaking issue at stake for a quantified employee self's identity and well-being is whether or not they feel that they belong and are recognized in a particular data-driven workplace, something which will affect turnover versus retention decisions (Rothausen et al. 2017).

\section{Conclusions}

This article did not seek to provide an exhaustive review, but certainly to contribute to the literature on employment and the quantified self by integrating multidimensional types of literature as psychological, sociological and critical theoretical. In doing so, implications for employee well-being and identity were also considered, as well as issues of system design and application. Finally, a fourth perspective of embodied sensemaking was elaborated and offered as a pragmatic way of incorporating and balancing the intimate-psychological versus societal-discursive emphases of the three other existing research approaches. This can be achieved principally through a focus on conditions of interpretation (i.e., of data, experience, discourse, self/others, the body, emotion/affect etc.) Limitations should be noted again here about the possible divisions and variety within the disciplinary approaches covered. Future research on the quantified self and big data should consider various alternative ways of integrating the literature, which are surely needed. Integration, as outlined here, should involve pragmatic but critical efforts to cross multiple levels of analysis (e.g., individual, organizational, 
and societal) and to balance the autonomy and rationality of individual users with wider structural conditions of work, employment and control.

The quantified self is a challenging area to review, given the fragmented evolving nature of the relevant literatures. Other reviews might draw more on other important literatures related to the quantified self-such as the history and norms of scientific knowledge production with data (Gibbons et al. 1994) and the sociology of technology and work, job and employment patterns in labor markets (Wood et al. 2019). There are also complexities with related language (e.g., self-tracking), role distinctions (e.g., employee versus consumer), and domains of application (e.g., employment, healthcare, sport).

As just one big data trend, this also makes it difficult to precisely isolate concrete examples and applied case studies. However, Alex Pentland's MIT-based study on big data and 'social physics' provided many workplace examples of quantifying co-worker body language, coffee breaks, commuting patterns and signals of depression at work for insights and adjustments (Pentland 2015). Other examples include professional bankers and software engineers improving their sleep patterns and moods based on individual data experiments, and expert patients and startups pooling data to better treat conditions like asthma, alcoholism and Parkinson's (The Economist 2012). More dedicated and thorough case examples and applications are needed, and it is hoped that this article will aid in the cumulative organization and presentation of knowledge on the topic. A single case could be looked at using multiple perspectives presented in this article, or multiple cases could be mapped across multiple perspectives to emphasize alternative self-quantification contexts and effects.

The topic is likely to evolve along many horizons and frontiers, not all of which can be readily addressed within single articles. If it is safe to assume that workplaces will become more populated by sensors and connected devices and objects, and design principles for a user-friendly personalized experience of the quantified employee self will only become more important (Mathur et al. 2015b). As with traditional job design, the key ethical and motivational employee issue is the tension surrounding autonomy-self-tracking makes employees more freely transparent to themselves but limits their freedom by making them more observable to others (Lanzing 2016). Norms for radical self-disclosure and intense self-presentation are likely to be tested, and quantifying relationships and communities seem likely to raise strident and valid concerns (Danaher et al. 2018). Yet, there are also great opportunities-disease prevention being one example (Barrett et al. 2013). As well as job design, other traditional frameworks for addressing employee well-being and motivation may be ripe for renewal in light of big data and quantified selves-for example, Grote and Guest (2017) have made a case for reinvigorating quality of working life (QWL) research. QWL was a prevalent agenda for employee well-being in the 1960s-1970s, particularly focused on criteria for meeting a range of employee needs around ensuring fair, safe, and high-quality working conditions.

Where regulation and legal scrutiny fail to keep the pace with self-tracking, empirical evidence consulting users directly and specifically about the forms of privacy and sharing they value seems crucial (Spiller et al. 2018). Organizations should have some incentive to do this too, given that the quantified self could pose threats to enterprise security if employees are following a bring your own device (BYOD) or wear your own device (WYOD) policy to interface with a company system during work hours (Caldwell 2014). The legal challenges revolve around similar issues-trying to define and scope the nature of the 'devices' and 'entities' that access and process personal biometric data (Hall 2014). The hope is that some regulatory frameworks will modernize and elaborate their coverage to acknowledge and clarify terms of ownership and rights for these more intangible data assets.

Overall, workplaces and employees could organize their digital and well-being agendas around the three frontiers identified by Rapp and colleagues (Rapp et al. 2015, 2016, 2017)—finding new ways for engaging users, going beyond numbers, and exploring understudied categories of users. In line with the sensemaking perspective proposed in the latter part of this article, multidimensional explanations and evaluations of quantification activities and contexts rooted in social embodied experiences are needed 
(Lupton et al. 2018; Puussaar et al. 2017). Otherwise, user engagement with the quantified self will fail to gain further traction, and our insights into its significance and applications will remain limited.

Funding: This research received no external funding.

Conflicts of Interest: The author declares no conflict of interest.

\section{References}

Adler, Paul S., Linda C. Forbes, and Hugh Willmott. 2007. Critical management studies. The Academy of Management Annals 1: 119-79. [CrossRef]

Ajana, Btihaj. 2017. Digital health and the biopolitics of the Quantified Self. Digital Health 3. Available online: https://journals.sagepub.com/doi/full/10.1177/2055207616689509 (accessed on 15 June 2019). [CrossRef] [PubMed]

Allard-Poesi, Florence. 2005. The paradox of sensemaking in organizational analysis. Organization 12: $169-96$. [CrossRef]

Angrave, David, Andy Charlwood, Ian Kirkpatrick, Mark Lawrence, and Mark Stuart. 2016. HR and analytics: Why HR is set to fail the big data challenge. Human Resource Management Journal 26: 1-11. [CrossRef]

Ayobi, Amid, Paul Marshall, and Anna L. Cox. 2016. Reflections on 5 years of personal informatics: Rising concerns and emerging directions. In Proceedings of the 2016 CHI Conference Extended Abstracts on Human Factors in Computing Systems. New York: ACM, pp. 2774-81.

Baerg, Andrew. 2017. Big data, sport, and the digital divide: Theorizing how athletes might respond to big data monitoring. Journal of Sport and Social Issues 41: 3-20. [CrossRef]

Bakke, John, and Cynthia Bean. 2013. The materiality of sensemaking. Tamara: Journal for Critical Organization Inquiry 5. Available online: http://tamarajournal.com/index.php/tamara/article/view/264 (accessed on 20 June 2019).

Barrett, Meredith A., Olivier Humblet, Robert A. Hiatt, and Nancy E. Adler. 2013. Big data and disease prevention: From quantified self to quantified communities. Big Data 1: 168-75. [CrossRef]

Barta, Kristen, and Gina Neff. 2016. Technologies for Sharing: Lessons from Quantified Self about the political economy of platforms. Information, Communication \& Society 19: 518-31.

Baumeister, Roy, Kathleen Vohs, and David Funder. 2007. Psychology as the science of self-reports and finger movements: Whatever happened to actual behavior? Perspectives on Psychological Science 2: 396-403. [CrossRef]

Becker, Karen, and Michelle Smidt. 2016. A risk perspective on human resource management: A review and directions for future research. Human Resource Management Review 26: 149-65. [CrossRef]

Belk, Russell. 2016. Extended self and the digital world. Current Opinion in Psychology 10: 50-54. [CrossRef]

Bersin, Josh. 2014. Quantified self: Meet the quantified employee. Forbes. June 25 . Available online: https://www.forbes.com/sites/joshbersin/2014/06/25/quantified-self-meet-the-quantified-employee/ \#690fc1dc5fe4 (accessed on 4 September 2019).

Bietz, Matthew, Gillian Hayes, Margaret Morris, Heather Patterson, and Luke Stark. 2016. Creating meaning in a world of quantified selves. IEEE Pervasive Computing 15: 82-85. [CrossRef]

Brougham, David, and Jarrod Haar. 2018. Smart technology, artificial intelligence, robotics, and algorithms (STARA): Employees' perceptions of our future workplace. Journal of Management \& Organization 24: 239-57.

Caldwell, Tracey. 2014. The quantified self: A threat to enterprise security? Computer Fraud E Security 11: 16-20.

Calvard, Thomas. 2016. Big data, organizational learning, and sensemaking: Theorizing interpretive challenges under conditions of dynamic complexity. Management Learning 47: 65-82. [CrossRef]

Calvard, Thomas, and Katherine Sang. 2017. Complementing psychological approaches to employee well-being with a socio-structural perspective on violence in the workplace: An alternative research agenda. The International Journal of Human Resource Management 28: 2256-74. [CrossRef]

Catlaw, Thomas J., and Billie Sandberg. 2018. The quantified self and the evolution of neoliberal self-government: An exploratory qualitative study. Administrative Theory \& Praxis 40: 3-22.

Cederstrom, Carl, and Andre Spicer. 2017. Desperately Seeking Self-Improvement. New York: OR Books. 
Choe, Eun Kyoung, Nicole B. Lee, Bongshin Lee, Wanda Pratt, and Julie A. Kientz. 2014. Understanding quantified-selfers' practices in collecting and exploring personal data. In Proceedings of the SIGCHI Conference on Human Factors in Computing Systems. New York: ACM, pp. 1143-52.

Crawford, Kate, Jessa Lingel, and Tero Karppi. 2015. Our metrics, ourselves: A hundred years of self-tracking from the weight scale to the wrist wearable device. European Journal of Cultural Studies 18: 479-96. [CrossRef]

Cunliffe, Ann, and Chris Coupland. 2012. From hero to villain to hero: Making experience sensible through embodied narrative sensemaking. Human Relations 65: 63-88. [CrossRef]

Dale, Karen, and Gibson Burrell. 2014. Being occupied: An embodied re-reading of organizational 'wellness'. Organization 21: 159-77. [CrossRef]

Danaher, John, Sven Nyholm, and Brian D. Earp. 2018. The quantified relationship. The American Journal of Bioethics 18: 3-19. [CrossRef] [PubMed]

Davenport, Thomas, Jeanne Harris, and Jeremy Shapiro. 2010. Competing on talent analytics. Harvard Business Review 88: 52-58. [PubMed]

Davis, Matthew C., Rose Challenger, Dharshana N. W. Jayewardene, and Chris W. Clegg. 2014. Advancing socio-technical systems thinking: A call for bravery. Applied Ergonomics 45: 171-80. [CrossRef] [PubMed]

Day, Arla, Natasha Scott, and Kevin Kelloway. 2010. Information and communication technology: Implications for job stress and employee well-being. In New Developments in Theoretical and Conceptual Approaches to Job Stress. Bingley: Emerald Group Publishing Limited, pp. 317-50.

Didžiokaitè, Gabija, Paula Saukko, and Christian Greiffenhagen. 2018. The mundane experience of everyday calorie trackers: Beyond the metaphor of Quantified Self. New Media E Society 20: 1470-87.

Elias, Ana Sofia, and Rosalind Gill. 2018. Beauty surveillance: The digital self-monitoring cultures of neoliberalism. European Journal of Cultural Studies 21: 59-77. [CrossRef]

Elkjaer, Bente, and Barbara Simpson. 2011. Pragmatism: A lived and living philosophy. What can it offer to contemporary organization theory? Philosophy and Organization Theory 32: 55-84.

Elsden, Chris, David S. Kirk, and Abigail C. Durrant. 2016. A quantified past: Toward design for remembering with personal informatics. Human-Computer Interaction 31: 518-57. [CrossRef]

Fineman, Stephen. 2006. Accentuating the positive? Academy of Management Review 31: 306-8. [CrossRef]

Fleming, Peter, and Andrew Sturdy. 2009. “Just be yourself!” Towards neo-normative control in organisations? Employee Relations 31: 569-83. [CrossRef]

Fotopoulou, Aristea, and Kate O'Riordan. 2017. Training to self-care: Fitness tracking, biopedagogy and the healthy consumer. Health Sociology Review 26: 54-68. [CrossRef]

Gabriels, Katleen, and Mark Coeckelbergh. 2019. 'Technologies of the self and other': How self-tracking technologies also shape the other. Journal of Information, Communication and Ethics in Society. Available online: https://www.emerald.com/insight/content/doi/10.1108/JICES-12-2018-0094/full/html (accessed on 15 June 2019).

Galison, Peter, and Bruce Hevly, eds. 1992. Big Science: The Growth of Large-Scale Research. Palo Alto: Stanford University Press.

Gergen, Kenneth J. 1996. Technology and the self: From the essential to the sublime. In Constructing the Self in a Mediated Age. Edited by Debra Grodin and Thomas R. Lindlof. Beverly Hills: Sage, pp. 127-40.

Gibbons, Michael, Camille Limoges, Helga Nowotny, Simon Schwartzman, Peter Scott, and Martin Trow. 1994. The New Production of Knowledge: The Dynamics of Science and Research in Contemporary Societies. London: Sage.

Gilmore, James. 2016. Everywear: The quantified self and wearable fitness technologies. New Media $\mathcal{E}$ Society 18: 2524-39.

Grant, Adam, Marlys Christianson, and Richard Price. 2007. Happiness, health, or relationships? Managerial practices and employee well-being tradeoffs. Academy of Management Perspectives 21: 51-63. [CrossRef]

Grey, Christopher. 1994. Career as a project of the self and labour process discipline. Sociology 28: 479-97. [CrossRef]

Griffith, Terri L. 1999. Technology features as triggers for sensemaking. Academy of Management Review 24: 472-88. [CrossRef]

Griffiths, Mark. 2010. Internet abuse and internet addiction in the workplace. Journal of Workplace Learning 22: 463-72. [CrossRef]

Grote, Gudela, and David Guest. 2017. The case for reinvigorating quality of working life research. Human Relations 70: 149-67. [CrossRef] 
Hall, Timothy S. 2014. The quantified self movement: Legal challenges and benefits of personal biometric data tracking. Akron Intellectual Property Journal 7: 27-38.

Hassan, Lobna, Antonio Dias, and Juho Hamari. 2019. How motivational feedback increases user's benefits and continued use: A study on gamification, quantified-self and social networking. International Journal of Information Management 46: 151-62. [CrossRef]

Hoy, Matthew. 2016. Personal activity trackers and the quantified self. Medical Reference Services Quarterly 35: 94-100. [CrossRef]

Hummels, Caroline, and Jelle Van Dijk. 2015. Seven principles to design for embodied sensemaking. In Proceedings of the Ninth International Conference on Tangible, Embedded, and Embodied Interaction. New York: ACM, pp. 21-28.

Humphreys, Lee. 2018. The Qualified Self: Social Media and the Accounting of Everyday Life. Boston: MIT Press.

Iliadis, Andrew, and Isabel Pedersen. 2018. The fabric of digital life: Uncovering sociotechnical tradeoffs in embodied computing through metadata. Journal of Information, Communication and Ethics in Society 16: 311-27. [CrossRef]

Jasanoff, Sheila. 2003. Technologies of humility: Citizen participation in governing science. Minerva 41: $223-44$. [CrossRef]

Jetten, Jolanda, and S. Alexander Haslam. 2018. Not by behaviour alone: In defence of self-reports and 'finger movements'. Social Psychological Bulletin 13: e26196. Available online: https://doi.org/10.5964/spb.v13i2.26196 (accessed on 1 June 2019). [CrossRef]

Kark Smollan, Roy. 2006. Minds, hearts and deeds: Cognitive, affective and behavioural responses to change. Journal of Change Management 6: 143-58. [CrossRef]

Kenton, Will. 2018. Investopedia: Quantified Self. Available online: https://www.investopedia.com/terms/q/ quantified-self.asp (accessed on 1 June 2019).

Kersten-van Dijk, Elisabeth, Joyce Westerink, Femke Beute, and Wijnand IJsselsteijn. 2017. Personal informatics, self-insight, and behavior change: A critical review of current literature. Human-Computer Interaction 32: 268-96. [CrossRef]

Klein, Gary, Brian Moon, and Robert R. Hoffman. 2006. Making sense of sensemaking 1: Alternative perspectives. IEEE Intelligent Systems 21: 70-73. [CrossRef]

Kristensen, Dorthe Brogård, and Minna Ruckenstein. 2018. Co-evolving with self-tracking technologies. New Media E Society 20: 3624-40.

Kunze, Kai, Masakazu Iwamura, Koichi Kise, Seiichi Uchida, and Shinichiro Omachi. 2013. Activity recognition for the mind: Toward a cognitive "Quantified Self". Computer 46: 105-8. [CrossRef]

Lambert, Alex. 2016. Bodies, mood and excess: Relationship tracking and the technicity of intimacy. Digital Culture \& Society 2: 71-88.

Lanlehin, Rosemary. 2018. Self-tracking, governmentality, and Nursing and Midwifery Council's (2016) revalidation policy. Nurse Education Today 64: 125-29. [CrossRef]

Lanzing, Marjolein. 2016. The transparent self. Ethics and Information Technology 18: 9-16. [CrossRef]

Lavallière, Martin, Arielle A. Burstein, Pedro Arezes, and Joseph F. Coughlin. 2016. Tackling the challenges of an aging workforce with the use of wearable technologies and the quantified-self. Dyna 83: 38-43. [CrossRef]

Lee, Victor. 2013. The Quantified Self (QS) movement and some emerging opportunities for the educational technology field. Educational Technology 53: 39-42.

Levina, Marina. 2012. Our Data, Ourselves: Feminist Narratives of Empowerment in Health 2.0 Discourse. In Cyberfeminism 2.0. Edited by Radhika Gajjala and Yeon J. Oh. New York: Peter Lang, pp. 13-29.

Levy, Karen. 2013. Relational big data. Stanford Law Review 66: 73-80.

Loch, Christoph, Fabian Sting, Nikolaus Bauer, and Helmut Mauermann. 2010. How BMW is defusing the demographic time bomb. Harvard Business Review. Available online: https://hbr.org/2010/03/the-globe-howbmw-is-defusing-the-demographic-time-bomb (accessed on 5 July 2019).

Lomborg, Stine, and Kirsten Frandsen. 2016. Self-tracking as communication. Information, Communication $\mathcal{E}$ Society 19: 1015-27.

Lupton, Deborah. 2014. Self-tracking cultures: Towards a sociology of personal informatics. In Proceedings of the 26th Australian Computer-Human Interaction Conference on Designing Futures: The Future of Design. New York: ACM, pp. 77-86.

Lupton, Deborah. 2016a. You are your data: Self-tracking practices and concepts of data. In Lifelogging: Theoretical Approaches and Case Studies about Self-Tracking. Edited by Stefan Selke. Berlin: Springer. 
Lupton, Deborah. 2016b. The diverse domains of quantified selves: Self-tracking modes and dataveillance. Economy and Society 45: 101-22. [CrossRef]

Lupton, Deborah. 2016c. The Quantified Self. London: John Wiley \& Sons.

Lupton, Deborah. 2017. Wearable devices: Sociotechnical imaginaries and agential capacities. In Embodied Technology: Wearables, Implantables, Embeddables, Ingestibles. Edited by Isabel Pedersen and Andrew Iliadis. Cambridge: MIT Press, Available online: https://www.researchgate.net/profile/Deborah_Lupton/ publication/321670531_Wearable_Devices_Sociotechnical_Imaginaries_and_Agential_Capacities/links/ 5a2a4ed90f7e9b63e5356a5c/Wearable-Devices-Sociotechnical-Imaginaries-and-Agential-Capacities.pdf (accessed on 10 June 2019).

Lupton, Deborah, and Sarah Maslen. 2018. The more-than-human sensorium: Sensory engagements with digital self-tracking technologies. The Senses and Society 13: 190-202. [CrossRef]

Lupton, Deborah, Sarah Pink, Christine Heyes Labond, and Shanti Sumartojo. 2018. Personal data contexts, data sense, and self-tracking cycling. International Journal of Communication 12: 647-66.

Lyall, Ben, and Brady Robards. 2018. Tool, toy and tutor: Subjective experiences of digital self-tracking. Journal of Sociology 54: 108-24. [CrossRef]

Lycett, Mark. 2013. 'Datafication': Making sense of (big) data in a complex world. European Journal of Information Systems 22: 381-86. [CrossRef]

Majmudar, Maulik D., Lina Avancini Colucci, and Adam B. Landman. 2015. The quantified patient of the future: Opportunities and challenges. Healthcare 3: 153-56. [CrossRef]

Maragiannis, Anastasios, and Rain Ashford. 2019. Diversity and inclusivity in the age of wearables: A buzzword, a myth, an uncertain reality. Body, Space E Technology 18: 198-214.

Maslen, Sarah. 2017. Layers of sense: The sensory work of diagnostic sensemaking in digital health. Digital Health 3. Available online: https://journals.sagepub.com/doi/full/10.1177/2055207617709101 (accessed on 15 June 2019). [CrossRef] [PubMed]

Mathur, Akhil, Marc Van den Broeck, Geert Vanderhulst, Afra Mashhadi, and Fahim Kawsar. 2015a. Quantified workplace: Opportunities and challenges. In Proceedings of the 2nd Workshop on Workshop on Physical Analytics. New York: ACM, pp. 37-41.

Mathur, Akhil, Marc Van den Broeck, Geert Vanderhulst, Afra Mashhadi, and Fahim Kawsar. 2015b. Tiny habits in the giant enterprise: Understanding the dynamics of a quantified workplace. In Proceedings of the 2015 ACM International Joint Conference on Pervasive and Ubiquitous Computing. New York: ACM, pp. 577-88.

McAfee, Andrew, and Erik Brynjolfsson. 2012. Big data: The management revolution. Harvard Business Review 90: 60-66. [PubMed]

McDougall, Allan, Elizabeth Anne Kinsella, Mark Goldszmidt, Karen Harkness, Patricia Strachan, and Lorelei Lingard. 2018. Beyond the realist turn: A socio-material analysis of heart failure self-care. Sociology of Health E Illness 40: 218-33.

Mettler, Tobias, and Jochen Wulf. 2019. Physiolytics at the workplace: Affordances and constraints of wearables use from an employee's perspective. Information Systems Journal 29: 245-73. [CrossRef]

Miller, Carl. 2019. Would you recognise yourself from your data? BBC News. Available online: https: //www.bbc.co.uk/news/technology-48434175 (accessed on 1 June 2019).

Moore, Phoebe. 2017. The Quantified Self in Precarity: Work, Technology and What Counts. London: Routledge.

Moore, Phoebe V. 2018. Tracking affective labour for agility in the quantified workplace. Body \& Society 24: 39-67.

Moore, Phoebe, and Lukasz Piwek. 2017. Regulating wellbeing in the brave new quantified workplace. Employee Relations 39: 308-16. [CrossRef]

Moore, Phoebe, and Andrew Robinson. 2016. The quantified self: What counts in the neoliberal workplace. New Media E Society 18: 2774-92.

Nagy, Peter, and Bernadett Koles. 2014. The digital transformation of human identity: Towards a conceptual model of virtual identity in virtual worlds. Convergence 20: 276-92. [CrossRef]

Neff, Gina, and Dawn Nafus. 2016. Self-Tracking. Boston: MIT Press.

Nowotny, Helga. 2010. Insatiable Curiosity: Innovation in a Fragile Future. Cambridge: MIT Press.

Orlikowski, Wanda J., and Susan V. Scott. 2008. Sociomateriality: Challenging the separation of technology, work and organization. The Academy of Management Annals 2: 433-74. [CrossRef]

Pentland, Alex. 2015. Social Physics: How Social Networks Can Make Us Smarter. London: Penguin. 
Ploderer, Bernd, Wolfgang Reitberger, Harri Oinas-Kukkonen, and Julia Gemert-Pijnen. 2014. Social interaction and reflection for behaviour change. Personal and Ubiquitous Computing 18: 1667-76. [CrossRef]

Plouffe, Christopher, Willy Bolander, Joseph Cote, and Bryan Hochstein. 2016. Does the customer matter most? Exploring strategic frontline employees' influence of customers, the internal business team, and external business partners. Journal of Marketing 80: 106-23. [CrossRef]

Puussaar, Aare, Adrian K. Clear, and Peter Wright. 2017. Enhancing personal informatics through social sensemaking. In Proceedings of the 2017 CHI Conference on Human Factors in Computing Systems. New York: ACM, pp. 6936-42.

Rapp, Amon, and Federica Cena. 2016. Personal informatics for everyday life: How users without prior self-tracking experience engage with personal data. International Journal of Human-Computer Studies 94: 1-17. [CrossRef]

Rapp, Amon, and Maurizio Tirassa. 2017. Know thyself: A theory of the self for personal informatics. Human-Computer Interaction 32: 335-80. [CrossRef]

Rapp, Amon, Federica Cena, Judy Kay, Bob Kummerfeld, Frank Hopfgartner, Till Plumbaum, and Jakob Eg Larsen. 2015. New frontiers of quantified self: Finding new ways for engaging users in collecting and using personal data. In Adjunct Proceedings of the 2015 ACM International Joint Conference on Pervasive and Ubiquitous Computing and Proceedings of the 2015 ACM International Symposium on Wearable Computers. New York: ACM, pp. 969-72.

Rapp, Amon, Federica Cena, Judy Kay, Bob Kummerfeld, Frank Hopfgartner, Till Plumbaum, Jakob Eg Larsen, Daniel A. Epstein, and Rúben Gouveia. 2016. New frontiers of quantified self 2: Going beyond numbers. In 2016 ACM International Joint Conference on Pervasive and Ubiquitous Computing, UbiComp 2016. New York: Association for Computing Machinery.

Rapp, Amon, Federica Cena, Judy Kay, Bob Kummerfeld, Frank Hopfgartner, Till Plumbaum, Jakob Eg Larsen, Daniel A. Epstein, and Rúben Gouveia. 2017. New frontiers of quantified self 3: Exploring understudied categories of users. In Proceedings of the 2017 ACM International Joint Conference on Pervasive and Ubiquitous Computing and Proceedings of the 2017 ACM International Symposium on Wearable Computers on-UbiComp'17. New York: ACM Press, pp. 861-64.

Richards, Neil, and Jonathan King. 2013. Three paradoxes of big data. Stanford Law Review Online 66: 41-46.

Richardson, Steven, and Debra Mackinnon. 2018. Becoming your own device: Self-tracking challenges in the workplace. Canadian Journal of Sociology 43: 265-90.

Rivera Pelayo, Veronica. 2015. Design and Application of Quantified Self Approaches for Reflective Learning in the Workplace. Karlsruhe: KIT Scientific Publishing.

Roberts, Seth. 2012. The reception of my self-experimentation. Journal of Business Research 65: 1060-66. [CrossRef] Rosenblat, Alex, Tamara Kneese, and Danah Boyd. 2014. Workplace surveillance. Open Society Foundations' Future of Work Commissioned Research Papers. Available online: https://papers.ssrn.com/sol3/papers.cfm? abstract_id=2536605 (accessed on 25 June 2019).

Rothausen, Teresa J., Kevin E. Henderson, James K. Arnold, and Avinash Malshe. 2017. Should I stay or should I go? Identity and well-being in sensemaking about retention and turnover. Journal of Management 43: 2357-85. [CrossRef]

Rowson, Jonathan. 2011. Transforming behaviour change: Beyond nudge and neuromania. Royal Scottish Academy (RSA) Projects. Available online: https://www.thersa.org/globalassets/pdfs/reports/rsa-transformingbehaviour-change.pdf (accessed on 15 June 2019).

Sanders, Rachel. 2017. Self-tracking in the digital era: Biopower, patriarchy, and the new biometric body projects. Body E Society 23: 36-63.

Schall, Mark, Richard Sesek, and Laura Cavuoto. 2018. Barriers to the adoption of wearable sensors in the workplace: A survey of occupational safety and health professionals. Human Factors 60: 351-62. [CrossRef]

Schildt, Henri, Saku Mantere, and Joep Cornelissen. 2019. Power in sensemaking processes. Organization Studies. Available online: https://journals.sagepub.com/doi/full/10.1177/0170840619847718 (accessed on 25 June 2019).

Schüll, Natasha. 2016. Data for life: Wearable technology and the design of self-care. BioSocieties 11: 317-33. [CrossRef]

Shah, Naimatullah, Zahir Irani, and Amir Sharif. 2017. Big data in an HR context: Exploring organizational change readiness, employee attitudes and behaviors. Journal of Business Research 70: 366-78. [CrossRef]

Sharon, Tamar. 2017. Self-tracking for health and the quantified self: Re-articulating autonomy, solidarity, and authenticity in an age of personalized healthcare. Philosophy \& Technology 30: 93-121. 
Sharon, Tamar, and Dorien Zandbergen. 2017. From data fetishism to quantifying selves: Self-tracking practices and the other values of data. New Media \& Society 19: 1695-709.

Solon, Olivia. 2012. How much data did Facebook have on one man? 1,200 pages of data in 57 categories. WIRED Magazine. Available online: https://www.wired.co.uk/article/privacy-versus-facebook (accessed on 1 June 2019).

Spiller, Keith, Kirstie Ball, Arosha Bandara, Maureen Meadows, Ciaran McCormick, Bashar Nuseibeh, and Blaine A. Price. 2018. Data privacy: users' thoughts on quantified self personal data. In Self-Tracking. Edited by Bithaj Ajana. London: Palgrave Macmillan, pp. 111-24.

Stawarz, Katarzyna, Anna L. Cox, and Ann Blandford. 2015. Beyond self-tracking and reminders: Designing smartphone apps that support habit formation. In Proceedings of the 33rd Annual ACM Conference on Human Factors in Computing Systems. New York: ACM, pp. 2653-62.

Stein, Mari-Klara, Erica L. Wagner, Pamela Tierney, Sue Newell, and Robert D. Galliers. 2019. Datification and the pursuit of meaningfulness in work. Journal of Management Studies 56: 685-717. [CrossRef]

Swan, Melanie. 2012a. Health 2050: The realization of personalized medicine through crowdsourcing, the quantified self, and the participatory biocitizen. Journal of Personalized Medicine 2: 93-118. [CrossRef] [PubMed]

Swan, Melanie. 2012b. Sensor mania! The internet of things, wearable computing, objective metrics, and the quantified self 2.0. Journal of Sensor and Actuator Networks 1: 217-53. [CrossRef]

Swan, Melanie. 2013. The quantified self: Fundamental disruption in big data science and biological discovery. Big Data 1: 85-99. [CrossRef] [PubMed]

The Economist. 2012. The quantified self: Counting every moment. The Economist. May 3. Available online: https://www.economist.com/technology-quarterly/2012/03/03/counting-every-moment (accessed on 3 September 2019).

Till, Chris. 2014. Exercise as labour: Quantified self and the transformation of exercise into labour. Societies 4: 446-62. [CrossRef]

Van Dijk, Jelle, Remko Van Der Lugt, and Caroline Hummels. 2014. Beyond distributed representation: Embodied cognition design supporting socio-sensorimotor couplings. In Proceedings of the 8th International Conference on Tangible, Embedded and Embodied Interaction. New York: ACM, pp. 181-88.

Walby, Kevin, and Mike Larsen. 2012. Access to information and freedom of information requests: Neglected means of data production in the social sciences. Qualitative Inquiry 18: 31-42. [CrossRef]

Walker, Benjamin, and Dan Caprar. 2019. When performance gets personal: Towards a theory of performance-based identity. Human Relations. Available online: https://journals.sagepub.com/doi/full/10.1177/0018726719851835 (accessed on 15 June 2019).

Weick, Karl E. 1995. Sensemaking in Organizations. London: Sage.

West, Peter, Richard Giordano, Max Van Kleek, and Nigel Shadbolt. 2016. The quantified patient in the doctor's office: Challenges \& opportunities. In Proceedings of the 2016 CHI Conference on Human Factors in Computing Systems. New York: ACM, pp. 3066-78.

Whitson, Jennifer R. 2013. Gaming the quantified self. Surveillance E Society 11: 163-76.

Whitson, Jennifer R. 2014. Foucault's Fitbit: Governance and Gamification. In The Gameful World-Approaches, Issues, Applications. Edited by Steffen P. Walz and Sebastian Deterding. Cambridge: MIT Press, pp. 339-58.

Wilson, H. James. 2013. Wearables in the workplace. Harvard Business Review 91: 27.

Wissinger, Elizabeth. 2017. Wearable tech, bodies, and gender. Sociology Compass 11: e12514. Available online: https://onlinelibrary.wiley.com/doi/full/10.1111/soc4.12514 (accessed on 15 June 2019). [CrossRef]

Wood, Alex J., Mark Graham, Vili Lehdonvirta, and Isis Hjorth. 2019. Good gig, bad gig: Autonomy and algorithmic control in the global gig economy. Work, Employment and Society 33: 56-75. [CrossRef] [PubMed]

Woodcock, Jamie, and Mark R. Johnson. 2018. Gamification: What it is, and how to fight it. The Sociological Review 66: 542-58. [CrossRef]

Zuboff, Shoshana. 2015. Big other: Surveillance capitalism and the prospects of an information civilization. Journal of Information Technology 30: 75-89. [CrossRef]

(C) 2019 by the author. Licensee MDPI, Basel, Switzerland. This article is an open access article distributed under the terms and conditions of the Creative Commons Attribution (CC BY) license (http://creativecommons.org/licenses/by/4.0/). 